\title{
Driving spaceship Earth
}

\author{
Designing policies to maintain human wellbeing within the limits of planet Earth is a daunting task, but scholars \\ and policymakers should embrace the challenge now.
}

$\mathrm{T}$ his month, Nature Sustainability celebrates its first anniversary. A year since we launched, relentlessly building our content and responding proactively to the needs of the community, we have a lot to be proud of. It has been an exciting journey, at times challenging and tiring, but definitely worthwhile. And we are keen to continue growing and exploring new avenues to give voice to the best sustainability scholarship and practice from across perspectives and geographies. Over the 12 issues in 2018, we have covered a variety of topics including agriculture, food security, sustainable diets, water use and management, air pollution, land use, ecosystem services, waste management, post-disaster reconstruction, conservation, technological solutions and many more. And we have also seen recurrent themes through our pages, such as the resource nexus, synergies and trade-offs among the sustainable development goals, planetary boundaries, and the role of interdisciplinary research in advancing sustainability debates and policies.

And how to design effective policies for sustainability is no doubt a key theme for our journal. Policies are the backbone of countries' development paths, as all societal actors need rules and legal frameworks to operate safely while striving to secure a good life. Successful sustainability policies hinge on an in-depth understanding of the multiple facets of the humannature relationship. Developing such an understanding goes back to the first contributions that brought sustainability to the attention of the general public during the 1960s and 1970s. The first economist, perhaps not so well known today, to dive into the complexities of sustainability was Kenneth E. Boulding. In 1964, he wrote about the great transition from a civilized to a post-civilized society ${ }^{1}$ and later, in 1966, he deepened his thinking around the transition from the idea of an open-earth system with infinite reservoirs (the cowboy economy) to that of a closed-earth system without infinite reservoirs (the spaceman economy $)^{2}$. In the former system, success is achieved by maximizing throughput, whereas in the latter throughput should be minimized. A few big thinkers at the time cultivated similar views on humanity's handling of natural resources and the need for a fundamental shift in perspective when it comes to securing human wellbeing over time. Buckminster Fuller ${ }^{3}$ imagined planet Earth as a spaceship driven by humans as the astronauts - it was already apparent in 1968 how humans managed to derail it from its natural course. And our driving abilities have not improved that much as of today. The idea of a closed, limited system was much emphasized by the Club of Rome in their famous book The Limits to Growth ${ }^{4}$, where the authors modelled the interactions between population growth, industrialization, resource demand, pollution and food production to show that drawing resources from the natural world indefinitely to sustain economic growth is simply not feasible. Even when they factored in technological progress, their extrapolations of continuing with businessas-usual trends still looked dire.

Since those years of raising awareness about humanity's challenges in a finite world, we have not achieved enough progress, and setting societies and economies on a truly sustainable development path is still more of an aspiration than a reality. Against this backdrop, a Perspective by Sterner and colleagues discusses the challenges of designing policies for the current geological era, the Anthropocene, dominated by human activity. The article is packed with thoughts about the extent to which the complexities of human-nature interactions should be reflected in sustainability-oriented policies. Their discourse is placed within the context of planetary boundaries research ${ }^{5}$, a scholarly domain focusing on identifying critical 'safe' boundaries for processes determining the state of the Earth system. Transgressing any boundary would increase the risk of catastrophic change. According to Sterner and co-authors, the main motivation behind sustainability policies is precaution; a policy is introduced to limit the risk of crossing one or more boundaries. The overarching message is simple, yet powerful - we do not need to look for new policy instruments, we need to use more wisely and effectively the ones available. The authors offer a number of suggestions on how to best design such policies and include examples of successful policies, but they warn readers about the role of politics in policymaking. In order for a policy instrument, for example a carbon tax or a renewable energy subsidy, to be successful, it needs to minimize political resistance. As an example, they refer to the case of some European green tax reforms that gained political acceptance by reducing some nongreen taxes, and therefore reducing voters' tax burden elsewhere.

There is urgent need for more research and lessons-learned exercises to better inform policymakers on how to design and implement sustainability policies. Given the complexities involved, there is also a need for stronger collaborations across diverse scholarly domains and practices, so that a more complete understanding of the intricate far-reaching problems of the Anthropocene can be developed. Finally, we need much more effective communication and dissemination channels between research and policymaking, in order to ensure that interventions are successful. We hope that the Perspective by Sterner and colleagues will stimulate debate and further thinking in this direction. We are ready to feature the best forthcoming work about safely driving spaceship Earth.

Published online: 10 January 2019 https://doi.org/10.1038/s41893-018-0217-7

\footnotetext{
References

1. Boulding, K. E. The Meaning of the Twentieth Century: The Great Transition (Harper and Row, 1964).

2. Boulding, K. E. In Environmental Quality in a Growing Economy (ed. Jarrett, H.) 3-14 (Resources for the Future, Johns Hopkins University Press, Baltimore, 1966).

3. Fuller, B. Operating Manual for Spaceship Earth (Lars Muller Publishers, 1968).

4. Meadows, D. H., Randers, J., Meadows, D. L. \& Behrens III, W. W. The Limits to Growth (Club of Rome, Universe Books, 1972).

5. Rockström, J. et al. Nature 461, 472-475 (2009).
} 